\title{
A new okicenone analog from Streptomyces sp. NEAU-W13
}

\author{
Xiang-Jing Wang ${ }^{1}$, Zhi-Dan Xiang ${ }^{1}$, Dian-Liang Gong ${ }^{1}$, Ji-Dong Wang ${ }^{2}$, Chong-Xi Liu ${ }^{1}$, Zhao-Xiang Zhu ${ }^{1}$, \\ Yi-Jun Yan $^{1}$ and Wen-Sheng Xiang ${ }^{1}$
}

The Journal of Antibiotics (2011) 64, 459-460; doi:10.1038/ja.2011.22; published online 30 March 2011

Keywords: cytotoxic activity; okicenone analog; Streptomyces sp. NEAU-W13; structure elucidation

The search for novel antibiotics and other bioactive microbial metabolites for potential pharmaceutical, agricultural and industrial applications has been and still is important. ${ }^{1-6}$ As part of our continuous effort to discover microorganism-derived anti-tumor secondary metabolites, we investigated the bioactive constituents of a strain Streptomyces sp. NEAU-W13. As a result, a new okicenone analog (1, Figure 1) was isolated from the fermentation broth of the strain. In this paper, the isolation, structure determination and cytotoxic activity of compound $\mathbf{1}$ are described.

Strain NEAU-W13 was isolated from a soil sample collected from a farmland located in Haicheng, Liaoning province, China. The organism was isolated using the standard dilution plate method and grown on humic acid-vitamin $\operatorname{agar}^{7}$ supplemented with nystatin $\left(50 \mathrm{mgl}^{-1}\right)$ and nalidixic acid $\left(20 \mathrm{mgl}^{-1}\right)$. The strain was identified as the genus Streptomyces because its 16S rRNA sequence (accession no: HQ596202 in the GenBank, National Center for Biotechnology Information) exhibited a high-sequence similarity of $99 \%$ with that of Streptomyces thermocarboxydus AT37 (accession no: NR026072).

The strain was maintained on the YMS medium containing $1 \%$ soluble amylum, $0.2 \%$ yeast extract, $0.1 \% \mathrm{KNO}_{3}$ and $2 \%$ agar, $\mathrm{pH} 7.0$. The seed medium consisted of $2 \%$ glucose, $1.5 \%$ soybean flour and $0.5 \%$ yeast autolysate, $\mathrm{pH}$ 7.0. All the media were sterilized at $121^{\circ} \mathrm{C}$ for $20 \mathrm{~min}$. Slant culture was incubated for $6-8$ days at $28^{\circ} \mathrm{C}$. A total of $10 \mathrm{ml}$ of sterile water was added to the slant of the YMS medium. The spores were scraped and transferred into a sterile tube containing glass beads; the spore suspension was then filtered through six layers of sterile filter cheesecloth and adjusted to $10^{7}-10^{8}$ c.f.u $\mathrm{ml}^{-1}$. A volume of $2.0 \mathrm{ml}$ of the spore suspension was inoculated into a $250-\mathrm{ml}$ flask containing $25 \mathrm{ml}$ of seed medium and incubated at $28^{\circ} \mathrm{C}$ for $24 \mathrm{~h}$, shaken at 250 r.p.m. Then, $8 \mathrm{ml}$ of the culture was transferred into a 1-1 Erlenmeyer flask containing $100 \mathrm{ml}$ of the producing medium consisting of $0.5 \%$ glucose, $1.5 \%$ lactose, $2.0 \%$ cotton seed powder and $0.3 \% \mathrm{CaCO}_{3}, \mathrm{pH} 7.0$, before sterilization. Fermentation was carried out at $28^{\circ} \mathrm{C}$ for 7 days on a rotary shaker at 250 r.p.m.
The fermentation broth (301) was centrifuged to separate mycelial cake and supernatant. The mycelial cake was extracted with $\mathrm{MeOH}$ (5.01) and the supernatant was applied to Diaion HP-20 (Mitsubishi Chemicals Company, Tokyo, Japan) and eluted with 95\% EtOH. The combined $\mathrm{MeOH}$ soluble and the $\mathrm{EtOH}$ eluates were concentrated under reduced pressure to give $40 \mathrm{~g}$ of crude extract. The crude extract was subjected to a silica gel column $(90 \times 5 \mathrm{~cm}$ i.d.; Qingdao Haiyang Chemical Group, Qingdao, China; 100-200 mesh) and eluted with $\mathrm{CHCl}_{3} / \mathrm{MeOH}$ mixture (98:2-70:30, v/v). The active fraction showing cytotoxic activity against the tumor cell line A549 was collected and evaporated to give $830 \mathrm{mg}$ of residue. The residue was chromatographed on Sephadex LH-20 column (GE Healthcare, Glies, UK) and eluted with EtOH. Then, the active fraction was further isolated by semi-preparative HPLC (Agilent1100, Agilent, Palo Alto, CA, USA; column: Zorbax SB-C18, $5 \mu \mathrm{m}, 250 \times 9.4 \mathrm{~mm}$ i.d.) using a solvent of $\mathrm{CH}_{3} \mathrm{CN} / \mathrm{H}_{2} \mathrm{O}(75: 25, \mathrm{v} / \mathrm{v})$ with the flow rate of $1.5 \mathrm{ml} \mathrm{min}^{-1}$ at a room temperature to give compound $1\left(t_{\mathrm{R}} 9.3 \mathrm{~min}, 5.6 \mathrm{mg}\right)$. The structure of compound 1 was elucidated by extensive spectroscopic methods. The UV spectra were obtained on a Varian CARY 300 BIO spectrophotometer (Agilent). IR spectra were recorded on a Nicolet Magna FT-IR 750 spectrometer $\left(v_{\max }\right.$ in $\mathrm{cm}^{-1}$ ) (Madison, WI, USA); ${ }^{1} \mathrm{H}$ and ${ }^{13} \mathrm{C}$ NMR spectra were measured with a Bruker DRX-400 $(400 \mathrm{MHz}$ for ${ }^{1} \mathrm{H}$ and $100 \mathrm{MHz}$ for ${ }^{13} \mathrm{C}$ ) spectrometer (Rheinstetten, Germany). Chemical shifts are reported in p.p.m. $(\delta)$, using residual $\mathrm{CH}_{3} \mathrm{COCH}_{3}$ $\left(\delta_{\mathrm{H}} 2.05\right.$ p.p.m.; $\left.\delta_{\mathrm{C}} 29.0\right)$ as an internal standard, and coupling constants $(J)$ in Hz. The HRESI-MS spectra were taken on a Q-TOF Micro LC-MS-MS mass spectrometer (Milford, MA, USA).

Compound 1 was isolated as a yellow amorphous powder with UV $(\mathrm{EtOH}) \lambda_{\max } \mathrm{nm}(\log \varepsilon): 227$ (4.53), 274 (4.97) and 379 (4.28) and m.p. $135-137^{\circ} \mathrm{C}$. Its molecular formula was determined to be $\mathrm{C}_{17} \mathrm{H}_{18} \mathrm{O}_{4}$ on the basis of HRESI-MS at $m / z$ 287.1277 $[\mathrm{M}+\mathrm{H}]^{+}$ (calculated as 287.1278 for $\mathrm{C}_{17} \mathrm{H}_{19} \mathrm{O}_{4}$ ) in conjunction with NMR data (Table 1). The IR spectrum of $\mathbf{1}$ showed a hydroxyl absorption at

\footnotetext{
${ }^{1}$ Life Science \& Biotechnology Research Center, School of Life Science, Northeast Agricultural University, Harbin, PR China and ${ }^{2}$ Department of New Drug Screening, Zhejiang Hisun Pharmaceutical, Co., Ltd, Taizhou, Zhejiang, PR China

Correspondence: Professor W-S Xiang, School of Life Science, Northeast Agricultural University, No. 59 Mucai Street, Xiangfang District, Harbin 150030, PR China.

E-mail: xiangwensheng@yahoo.com.cn
}

Received 10 November 2010; revised 20 February 2011; accepted 21 February 2011; published online 30 March 2011 
<smiles>CCCc1cc(O)cc2cc3c(c(O)c12)C(=O)CCC3O</smiles>

Compound 1<smiles>Cc1cc(O)cc2cc3c(c(O)c12)C(=O)CCC3O</smiles>

Okicenone

Figure 1 Structures of 1 and okicenone.

Table $1{ }^{1} \mathrm{H}$ - and ${ }^{13} \mathrm{C}$-NMR data of compound 1 in acetone- $d_{6}$

\begin{tabular}{lccccc}
\hline No. ${ }^{13} \mathrm{C}$ (mult) & ${ }^{1} \mathrm{H}$ & No. & ${ }^{13} \mathrm{C}$ (mult) & ${ }^{1} \mathrm{H}$ \\
\hline 1 & $204.0(\mathrm{~s})$ & & $8 \mathrm{a}$ & $116.7(\mathrm{~s})$ & \\
$2 \mathrm{a}$ & $34.3(\mathrm{t})$ & $2.72(1 \mathrm{H}, \mathrm{m})$ & 9 & $166.4(\mathrm{~s})$ & \\
$2 \mathrm{~b}$ & & $2.93(1 \mathrm{H}, \mathrm{m})$ & $9 \mathrm{a}$ & $108.7(\mathrm{~s})$ & \\
$3 \mathrm{a}$ & $31.3(\mathrm{t})$ & $2.14(1 \mathrm{H}, \mathrm{m})$ & 10 & $115.3(\mathrm{~d})$ & $7.20(1 \mathrm{H}, \mathrm{s})$ \\
$3 \mathrm{~b}$ & & $2.29(1 \mathrm{H}, \mathrm{m})$ & $10 \mathrm{a}$ & $142.3(\mathrm{~s})$ & \\
4 & $67.2(\mathrm{~d})$ & $4.91(1 \mathrm{H}, \mathrm{m})$ & 11 & $39.0(\mathrm{t})$ & $3.26(2 \mathrm{H}, \mathrm{t}, \mathrm{J}=7.6 \mathrm{~Hz})$ \\
$4 \mathrm{a}$ & $141.1(\mathrm{~s})$ & & 12 & $25.2(\mathrm{t})$ & $1.72(2 \mathrm{H}, \mathrm{m})$ \\
5 & $108.7(\mathrm{~d})$ & $7.00(1 \mathrm{H}, \mathrm{d}, \mathrm{J}=2.5 \mathrm{~Hz})$ & 13 & $13.5(\mathrm{q})$ & $1.01(3 \mathrm{H}, \mathrm{t}, \mathrm{J}=7.4 \mathrm{~Hz})$ \\
6 & $158.7(\mathrm{~s})$ & & $4-\mathrm{OH}$ & & $4.56(1 \mathrm{H}, \mathrm{d}, \mathrm{J}=4.9 \mathrm{~Hz})$ \\
7 & $119.8(\mathrm{~d}) 6.91(1 \mathrm{H}, \mathrm{d}, \mathrm{J}=2.5 \mathrm{~Hz})$ & $6-\mathrm{OH}$ & & $9.11(1 \mathrm{H}, \mathrm{s})$ \\
8 & $145.9(\mathrm{~s})$ & & $9-\mathrm{OH}$ & & $15.5(1 \mathrm{H}, \mathrm{s})$ \\
\hline
\end{tabular}

$3375 \mathrm{~cm}^{-1} .{ }^{1} \mathrm{H}$ NMR data of 1 revealed two aromatic meta-coupled doublet protons at $\delta_{\mathrm{H}} 7.00(1 \mathrm{H}, \mathrm{d}, J=2.5 \mathrm{~Hz})$ and $6.91(1 \mathrm{H}, \mathrm{d}$, $J=2.5 \mathrm{~Hz})$ and one aromatic singlet signal at $\delta_{\mathrm{H}} 7.20(1 \mathrm{H}, \mathrm{s})$, one methyl triplet at $\delta_{\mathrm{H}} 1.01(3 \mathrm{H}, \mathrm{t}, J=7.4 \mathrm{~Hz})$, two phenolic hydroxyl singlets at $\delta_{\mathrm{H}} 15.5(1 \mathrm{H}, \mathrm{s})$ and $\delta_{\mathrm{H}} 9.11(1 \mathrm{H}, \mathrm{s})$, one hydroxyl doublet at $\delta_{\mathrm{H}} 4.56(1 \mathrm{H}, \mathrm{d}, J=4.9 \mathrm{~Hz})$, one oxymethine multiplet signal at $\delta_{\mathrm{H}} 4.91$ $(1 \mathrm{H}, \mathrm{m})$, as well as eight protons at $\delta_{\mathrm{H}} 1.72(2 \mathrm{H}, \mathrm{m}), 3.26(2 \mathrm{H}, \mathrm{t}), 2.14$ $(1 \mathrm{H}, \mathrm{m}), 2.29(1 \mathrm{H}, \mathrm{m}), 2.72(1 \mathrm{H}, \mathrm{m})$ and $2.93(1 \mathrm{H}, \mathrm{m})$. The ${ }^{13} \mathrm{C} \mathrm{NMR}$ and DEPT135 data (Table 1) of 1 exhibited one carbonyl carbon, three $s p^{2}$ methines, seven $s p^{2}$ quaternary carbons, one aliphatic oxymethine, four aliphatic methylenes and one methyl group. The sequence from $\delta_{\mathrm{H}} 1.01(\mathrm{H}-13)$ to $\delta_{\mathrm{H}} 3.26(\mathrm{H}-11)$ through $\delta_{\mathrm{H}} 1.72(\mathrm{H}-12)$ in ${ }^{1} \mathrm{H}-{ }^{1} \mathrm{H}$ COSY spectrum indicated the presence of a $n$-propyl moiety. By detailed analysis of the NMR data of $\mathbf{1}$, it was showed that $\mathbf{1}$ belongs to the 1,2,3,4-tretrahydro anthracene structure class with substituents of three hydroxyl groups, one $n$-propyl group and one carbonyl group (Figure 2). The correlated signals of $\delta_{\mathrm{H}} 4.91(\mathrm{H}-4)$ and $\delta_{\mathrm{H}} 2.14 / 2.29$ $(\mathrm{H}-3 \mathrm{a}, 3 \mathrm{~b}), \delta_{\mathrm{H}} 2.14 / 2.29(\mathrm{H}-3 \mathrm{a}, 3 \mathrm{~b})$ and $\delta_{\mathrm{H}} 2.72 / 2.93(\mathrm{H}-2 \mathrm{a}, 2 \mathrm{~b})$ in the ${ }^{1} \mathrm{H}-{ }^{1} \mathrm{H}$ COSY spectrum further confirmed the above conclusion. The whole structure assignment was supported by the ${ }^{1} \mathrm{H}-{ }^{1} \mathrm{H}$ COSY, heteronuclear multiple quantum coherence and $\mathrm{HMBC}$ experiments. In the $\mathrm{HMBC}$ spectrum (Figure 2), the correlations from $\mathrm{H}_{2}-2$ to a carbonyl carbon C-1 and a hydroxyl carbon C-4, and from $\mathrm{H}_{2}-3$ to C-1, C-4 and C-4a were established. A downfield hydroxyl signal at $\delta_{\mathrm{H}}$ $15.5(9-\mathrm{OH})$ and the HMBC correlations between $\delta_{\mathrm{H}} 15.5(9-\mathrm{OH})$ and C-9, C-9a and C-8a showed the hydroxyl group substituted at C-9. The linkage of $\mathrm{C}-11$ and $\mathrm{C}-8$ was evident from the $\mathrm{HMBC}$ correlations from $\mathrm{H}_{2}-12$ to $\mathrm{C}-8$, and from $\mathrm{H}_{2}-11$ to $\mathrm{C}-7, \mathrm{C}-8$ and C-8a. The metacoupling protons of $\mathrm{H}-5$ and $\mathrm{H}-7$ suggested that the remaining hydroxyl was located at C-6. The structure of 1 was very similar to

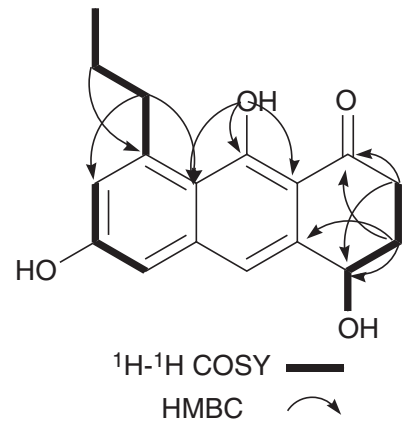

Figure 2 Key ${ }^{1} \mathrm{H}_{-}{ }^{1} \mathrm{H}$ COSY and $\mathrm{HMBC}$ correlations of 1 .

that of okicenone ${ }^{8}$ and was replaced a methyl at C-8 in okicenone with a $n$-propyl group. Furthermore, compound $\mathbf{1}$ and aloesaponol III 8-methyl ether ${ }^{9}$ have the same skeleton and one chiral center at C-4. The absolute stereochemistry of aloesaponol III 8-methyl ether has been solved by the extended benzoate chirality method as $(S) .{ }^{9}$ The attempt to differentiate the coupling constants between $\mathrm{H}-4$ and $\mathrm{H}_{2}-3$ was incomplete because of the multiplet of $\mathrm{H}-4$ in the ${ }^{1} \mathrm{H}$ NMR spectrum. In further NMR experiment, the proton signal of $4-\mathrm{OH}$ disappeared with the addition of $\mathrm{D}_{2} \mathrm{O}$ and the peak of $\mathrm{H}-4$ was displayed as a double doublet with two coupling constants $\left(J_{\mathrm{aa}}=8.1 \mathrm{~Hz}\right.$ and $J_{\mathrm{ae}}=3.3 \mathrm{~Hz}$ ). The two coupling constants between $\mathrm{H}-4$ and $\mathrm{H}_{2}-3$ revealed that the hydroxyl group at C-4 is quasi-equatorial, which is identical with that of aloesaponol III 8-methyl ether' ${ }^{9}$. The optical rotation $[\alpha]_{\mathrm{D}}^{25}+23.1$ (c 0.039 , EtOH) of 1 was also similar to that of aloesaponol III 8-methyl ether. This finalizes the study and allows us to report the structure of 1 as 1-oxo-4(S),6,9-trihydroxy-8- $n$-propyl1,2,3,4-tetrahydroanthracene.

We tested the inhibitory activity of compound 1 against the growth of human lung adenocarcinoma cell line A549 using the CCK-8 colorimetric method, as described in our previous paper. ${ }^{10}$ The result showed that compound $\mathbf{1}$ dose-dependently inhibited the growth of A549 cells with an $\mathrm{IC}_{50}$ value of $12.5 \mu \mathrm{g} \mathrm{ml}^{-1}$.

\section{ACKNOWLEDGEMENTS}

This work was supported by the National Key Project for Basic Research (No. 2010CB126102) and the National Natural Science Foundation of China (No. 30771427 and 31000884).

1 Takahashi, Y. \& Omura, S. Isolation of new actinomycete strains for the screening of new bioactive compounds. J. Gen. Appl. Microbiol. 49, 141-154 (2003).

2 Berdy, J. Bioactive microbial metabolites. J. Antibiot. 58, 1-26 (2005).

3 Butler, M. S. \& Buss, A. D. Natural products-the future scaffolds for novel antibiotics? Biochem. Pharmacol. 71, 919-929 (2006).

4 Luzhetskyy, A., Pelzer, S. \& Bechthold, A. The future of natural products as a source of new antibiotics. Curr. Opin. Investig. Drugs. 8, 608-613 (2007).

5 Demain, A. L. \& Sanchez, S. Microbial drug discovery: 80 years of progress. J. Antibiot. 62, 5-16 (2009).

6 Stefano, D., Sonia, M., Paolo, M., Margherita, S. \& Daniela, J. Antibiotic discovery in the twenty-first century: current trends and future perspectives. J. Antibiot. 63, 423-430 (2010).

7 Hayakawa, M. \& Nonomura, H. Humic acid-vitamin agar, a new medium for the selective isolation of soil actinomycetes. J. Fement. Technol. 65, 501-509 (1987).

8 Funayama, S., Ishibashi, M., Komiyama, K. \& Ômura, S. A new antibiotic, okicenone II. Physico-chemical properties and structure elucidation. J. Antibiot. 44, 819-823 (1991).

9 Yagi, A., Makino, K. \& Nishioka, I. Studies on the constituents of Aloe saponaria HAW. II. The structures of tetrahydroanthracene derivatives, Aloesaponol III and -IV. Chem. Pharm. Bull. 25, 1764-1770 (1977).

10 Wang, J. D., Yang, X. H., Zhou, Y., Wang, H. B. \& Bai, H. et al. HS071, a new furan-type cytotoxic metabolite from Streptomyces sp. HS-HY-071. J. Antibiot. 61, 623-626 (2008). 